\title{
Observations on muscle pain in man, with particular reference to pain during needle electromyography
}

\author{
J. C. MEADOWS
}

From the Department of Neurological Studies, The Middlesex Hospital, London

SUM MARY Muscle pain receptors have been studied in man. During the advance of an EMG needle pain is most regularly experienced as the muscle fascia is pierced. Further advancing the needle is usually quite painless. However, there are scantily distributed points within the muscle ('pain spots') which may give rise to pain if encountered by the advancing needle. The nature of the responsible receptors is obscure but it is likely that pain may sometimes be caused by activation of nerve fibres (presumably from these receptors) coursing through the muscle rather than by activation of the receptors themselves. Intramuscular bleeding is unlikely to contribute often to the pain of needle electromyography. Mechanically sensitive 'pain spots' are more painful than other areas when stimulated electrically or injected with hypertonic $(6 \%)$ saline. This suggests a common receptor. The high electrical threshold and relative invulnerability to pressure of afferent fibres from these receptors suggest that they are mainly of small diameter. These findings are discussed in relation to experimental work on pressure-pain receptors in animals.

There is no doubt that there are sensory receptors associated with skeletal muscle that may give rise to the sensation of pain. The pain of ischaemic exercise was studied many years ago by Lewis, Pickering, and Rothschild (1931) and shown to be due to accumulation of metabolites within the muscle. Lewis (1938) and Kellgren (1937-8) also investigated the pain produced by intramuscular injection of small amounts (less than $0.5 \mathrm{ml}$.) of 5-6\% sodium chloride. Lewis (1942) pointed out that both these forms of muscle pain, like the pain produced by squeezing a muscle, were of similar character and they might therefore be expected to be caused by activation of the same type of receptor.

Another form of muscle pain, familiar to those engaged in clinical electromyography (EMG), is that encountered during the insertion of a concentric needle electrode. When an EMG needle is inserted into a muscle, transient pain is usually experienced but, once the needle has come to rest, the subject may be unaware of its presence. Sometimes, however, the pain may last some seconds after needle movement is over and occasionally a mild, dull ache may persist much longer.

The nature of the receptors subserving muscle pain is not known. In the cat there are receptors within muscle which discharge during local pressure (Paintal, 1960; Iggo, 1961) but inconsistently if at all during stretch or muscular contraction, and Paintal has suggested that similar receptors might be responsible for the various types of muscle pain in man. The present paper describes some observations relevant to this suggestion which were made mainly during the course of a study on the effects of muscle percussion.

\section{METHODS}

Most of the following observations were made with concentric needle electrodes (Rank MED 150.7 and 150.6, of external diameter 0.46 and $0.30 \mathrm{~mm}$ respectively) in the author's vasti mediales during the course of an unrelated study on the effects of muscle percussion (Meadows, 1970). Pain sensitive spots ('pain spots') were occasionally encountered during the advance of the needle and the careful adjustments of needle position that were necessary during that investigation offered a good opportunity to study the site and nature of the responsible receptors. Unless otherwise stated, all observations were made away from the end-plate zone.

In other experiments, different forms of muscle pain were studied. Pain was induced by intramuscular electrical stimuli delivered from a Devices Type 3072 stimulator and connected to the two terminals of the needleelectrode, 
the inner core being the cathode, the outer casing the anode.

Osmotically induced pain was produced by injecting $0.1 \mathrm{ml}$. quantities of sterile $6 \%$ sodium chloride into the muscle through size 17 disposable needles.

In some experiments the nerve to vastus medialis was stimulated electrically or blocked with $2 \%$ xylocaine. To do this the rough position of the nerve in mid-thigh was first established by stimulating with surface electrodes. A size 26 injection needle (length $5 \mathrm{~cm}$ ), lacquered to its tip, was inserted through the skin, usually through a bleb of intradermal $2 \%$ xylocaine. The needle tip was then positioned as close as possible to the nerve by finding the site at which twitches could be obtained with minimal shock strengths (usually 5-20V, $0.05 \mathrm{msec}$ duration) delivered cathodally down the needle, the anode being provided by a distant plate electrode. When nerve blockade was desired, $2-5 \mathrm{ml} .2 \%$ xylocaine was injected down the needle.

\section{RESULTS}

PRELIMINARY OBSERVATIONS The pain experienced when a needle is thrust into a muscle has already been described. It usually subsides within a second or two but occasionally a mild dull ache may persist for half a minute or more. A similar dull ache may return when a needle has been in place for some minutes, as when recording from the small muscles of the hand or the calf muscles during repeated motor nerve stimulation. No doubt the movement caused by muscular contraction may contribute in these circumstances.

If the needle is slowly advanced through the skin into a muscle such as vastus medialis, pain is experienced on piercing the skin and again on piercing the muscle fascia, in the latter case having a duller and less well-localized character. Further advancing the needle is then usually quite painless. However, on infrequent occasions, a variably painful point may be reached during such a steady advance. If the needle is further advanced the pain usually subsides but in a few instances it was found to be so intense that further insertion was not attempted. Occasionally when the needle was critically positioned, the slightest pressure on its butt (insufficient to alter needle position permanently because of friction and the elastic properties of the tissues) caused intense pain which ceased as soon as the pressure was discontinued. When attention was directed to the point, it was sometimes apparent that the site of such pain spots coincided with an increase in resistance to the advancing needle, similar to that felt on encountering the muscle fascia when first entering the muscle. Since there was usually no doubt that the needle tip was within muscle it seems likely that such resistance is due to intramuscular fascial planes.

Further experiments were carried out with the needle in the region of the end-plate zone. In this region advancing the needle sometimes caused a stab of pain which was associated with a twitch of a small fascicle or sometimes a greater part of the muscle. This is almost certainly the result of piercing intramuscular nerve bundles.

PAIN PRODUCED BY ELECTRICAL STIMULATION THROUGH A CONCENTRIC NEEDLE ELECTRODE On two occasions with the needle tip particularly favourably positioned, immediately adjacent to an extremely painful spot in the muscle (so that the slightest pressure on its butt produced severe pain) electrical pulses of $0.05 \mathrm{msec}$ duration were delivered across the two terminals of the needle. Single pulses of less than $5 \mathrm{~V}$ produced a definite delayed discomfort and $10 /$ second stimulation produced severe pain. In these sites and with this strength of stimulus no visible muscular contraction could be seen. Stimulating at this strength in other areas of the muscle was quite painless, although with larger shock strengths pain could be elicited deep in the muscle. This was usually associated with local, visible contraction and presumably results from stimulation of intramuscular nerve fibres and bundles.

In other experiments brief trains of 10 shocks at $\overrightarrow{0}$ $100 /$ second were used, as this proved a particularly $\frac{\rho}{\Phi}$ 윽 effective pain stimulus. These trains were programmed by a Devices Digitimer. If a needle is thrust deeply into the muscle and is then withdrawn in 1 too 흘 $2 \mathrm{~mm}$ stages, and this is repeated in two or three different areas, the electrical threshold for pain atôे $\vec{\theta}$ each stage of the withdrawal with this stimulus may? be found to vary 10 to 20 -fold, reflecting the varying proximity of the needle tip to pain receptors or fibres coursing within the muscle.

PAIN PRODUCED BY INJECTION OF HYPERTONIC SALINE A few experiments were carried out in which hypertonic saline was injected into the vastus medialis away from the end-plate region. The needle was advanced slowly into the muscle and the discomfort at the point of coming to rest noted as absent, or present. (Painful spots were deliberately looked for, so that the relative incidence is biased in their favour.) When $0.1 \mathrm{ml}$. $6 \%$ sodium chloride was then injected a variable degree of pain was experienced on all but two occasions. This was roughly assessed into three grades: mild (barely perceptible), moderate, and severe (causing intense discomfort). It was found that the severity of mechanically induced pain related roughly to that produced by injection of hypertonic saline (Table).

PAIN AND INTRAMUSCULAR HAEMATOMAS Woolf (1969) has questioned the existence of intramuscular 
TABLE

DEGREES OF PAIN PRODUCED BY HYPERTONIC SALINE

\begin{tabular}{lccccc}
\hline Number & $\begin{array}{c}\text { Mechanically } \\
\text { induced } \\
\text { pain }\end{array}$ & \multicolumn{3}{c}{ Pain produced by hypertonic saline } \\
\cline { 2 - 6 } & Absent & Mild & Moderate & Severe \\
\hline 18 & Absent & 2 & 8 & 8 & 1 \\
10 & Prisent & 0 & 1 & 3 & 6 \\
\hline
\end{tabular}

pain receptors and has suggested that haemorrhage from tearing of small vessels may, by increasing intramuscular pressure, account for pain during needle electromyography. In the present study, palpable haematomas developed on three occasions in vastus medialis, each being felt as an ill-detined nodule about the size of a small hazel-nut. One was noticed when the needle position was being adjusted, the second was noticed because of a mild sensation closer to itch than to pain, and the third was found incidentally after the needle had been withdrawn. None gave rise to overt pain; neither was this caused by the application of heavy pressure to cause their dispersion.

On eight occasions, $1 \mathrm{ml}$. isotonic saline $(0.9 \%$ sodium chloride) was injected into a muscle over a 15 second period (vastus medialis on six occasions, vastus lateralis on two occasions). The needle was in place for 30 seconds before the injection, by which time any painful sensation from its presence had worn off. Immediately after the injection the needle was withdrawn and an ill-defined local swelling could then sometimes be felt. Mild pain resulted on two occasions and a short-lived 'sensation' on three others but the remaining three injections were quite symptomless.

Injection of saline might not have the same effect as blood. Accordingly in four further experiments $1 \mathrm{ml}$. blood was withdrawn from an antecubital vein and immediately injected into vastus medialis. All four injections were quite painless.

These observations make it unlikely that intramuscular haematomas contribute often to the pain of needle electromyography, at least in large muscles. It should be noted however, that the two saline injections which were painful were both in the most distal part of vastus medialis, where the muscle is approaching its insertion and where there is less room for expansion to occur. It may be that haemorrhage sometimes accounts for pain during electromyography in smaller, more compact muscles such as those of the hand, but even then clinical experience shows that haematomas are not always particularly painful.

NATURE OF AFFERENT FIBRES FROM MUSCLE PAIN RECEPTORS. In animals, the diameter and conduction velocity of afferent fibres from pressure-pain receptors can be determined by direct experimentation but this is not so readily achieved in man where a more indirect approach is required. Experiments were therefore carried out that relied upon the known differences between nerve fibres of different diameters such as their vulnerability to the effects of local anaesthetic and pressure, and their thresholds to electrical stimulation. Large fibres are less vulnerable to the effect of local anaesthetic and have lower electrical thresholds than small fibres but are more susceptible to pressure (Gasser and Erlange", 1929; Nathan and Sears, 1961).

In five experiments, the nerve to vastus medialis was stimulated with cathodal shocks through a needle lacquered to its tip and inserted in mid thigh with its tip as close as possible to the nerve. It was found that for pain to be felt, the stimulus strength had to be increased between three and seven times that required for a maximal twitch, as judged by surface EMG recording. Paintal found a seven- to 44-fold difference between the electrical threshold of single motor fibres and single fibres from pressure pain receptors in the cat hind limb, but a much smaller difference is to be expected by the present method of comparison.

In two experiments the ulnar nerve was deliberately compressed at the elbow until there was complete cutaneous anaesthesia to light touch in ulnar distribution and only minimal voluntary movement remaining in the hypothenar muscles. It was then still possible to produce pain within abductor digiti minimi with shocks delivered down a concentric needle electrode.

In further experiments, $1 \%$ xylocaine was injected around the nerve to vastus medialis in mid-thigh (two experiments) and around the ulnar nerve at the elbow (one experiment). In all three experiments, power (and the surface EMG response evoked by nerve stimulation above the block) began to decline before pain from intramuscular stimulation through a concentric needle electrode had been abolished.

With the exception of the experiments with local anaesthetic, these findings suggest that the afferent fibres subserving muscle pain are of substantially smaller diameter than most motor fibres to the muscle. The results with xylocaine block might be due to irregular penetration of the anaesthetic into the nerve (see Nathan and Sears, 1961) but might also occur if some pain-afferents were of large diameter.

\section{DISCUSSION}

In 1960 Paintal described receptors in the hind limb muscles of the cat which were activated by local 
pressure but only irregularly by contraction, muscle stretch, or asphyxia. He suggested that these receptors might subserve pain and that similar receptors might be responsible for some forms of muscle pain in man. Others-for example, Woolf (1969)-have been reluctant to accept that intramuscular mechanoreceptors subserving pain occur in man.

No one would dispute that pain is experienced during insertion of a needle in clinical electromyography but this is caused mainly when the surface fascia is pierced. However, the present study shows that scanty pain receptors exist also within muscle. Indeed, the conditions giving rise to pain when the needle was immediately adjacent to an intramuscular pain spot in the present experiments closely resemble Paintal's description of small displacements of a needle in and out producing an afferent discharge from a pressure-pain receptor in the cat. The term 'pain spot', as employed above, is used because it is apparent that pain during the passage of a needle can result from piercing of intramuscular nerve bundles rather than from activation of a specific end-receptor. Cutting an intramuscular nerve at muscle biopsy is painful (Woolf, 1969), and insertion of a needle in the region of the end-plate zone may cause a local twitch simultaneously with a spasm of pain. It is probable that pain experienced with a needle elsewhere in the muscle is sometimes due to activation of nerve fibres rather than their receptors, but if activation of nerve fibres gives rise to pain one may assume that the end-receptors do so also. It should be realized however that, as used, the term 'pain spot' is a relative one and merely implies sufficient proximity to an intramuscular pain-sensitive structure for movement to give rise to pain.

It seems, then, that intramuscular pain receptors and the nerve fibres serving them may be responsible for pain when it occurs during the advance of an EMG needle within a muscle. Intramuscular bleeding is unlikely to contribute often, at least in large muscles, for injection of blood or isotonic saline into the thigh muscles does not usually give rise to significant pain.

An additional point that emerges from the present investigation is that different painful stimuli may be effective at the same pain spots within the muscle. For example, electrical stimulation with the needle positioned adjacent to a mechanically sensitive painspot causes more discomfort than with the needle positioned away from such a spot. The same applies for intramuscular injections of hypertonic saline, which are a well-known cause of muscle pain(Lewis, 1938; Kellgren, 1937-8). The time course of the pain produced by hypertonic saline was similar to that obtained by Paintal (1960) for the discharge of impulses from pressure pain receptors in the cat when these are activated by hypertonic saline: it started after a few seconds and lasted up to five minutes.

Taken together, these results tend to support the view, based on Lewis's (1942) observations on pain due to muscle squeeze, injection of hypertonic saline and ischaemia, that pain receptors in muscle are of a single type. Ischaemic pain was not investigated in the present study, but the pain produced by needle movement within the muscle, and by hypertonic saline and electrical stimulation had a similar quality and, as already stated, the responsive sites within the muscle tended to be the same for the three types of stimuli. On the other hand, Paintal (1960) believes that ischaemic muscle pain must have a different mechanism because asphyxia for periods of up to an hour did not cause pressure-pain receptors to discharge in the cat. However, arterial occlusion produced by a sphygmomanometer cuff around the upper arm in man for periods in excess of half an hour does not give rise to muscle pain provided the limb is kept completely rested. Even with vigorous contraction of the forearm muscles it is many seconds before significant pain results. (It is noteworthy that some of Paintal's receptors dido discharge in the comparable conditions of tetanio stimulation combined with ischaemia). Possibl individual receptors do not fire very rapidly durin ischaemic muscle pain, but since all are presumably being activated to a comparable degree the collective effect might be considerable. It is questionable, there fore, whether Paintal's conclusion on ischaemi muscle pain is valid. However, there is some evidence that suggests the existence of more than one type of receptor-for example, Bessou and Laporte's (1961) demonstration that deeply placed receptors in the cat soleus have a slower rate of adaptation than receptors on the surface of the muscle and unlike the latter may give a low frequency discharge at the onset of stretch. For the moment this question remains unsolved but it is to be hoped that further experimentation will answer it.

The histological nature of the receptors is obscure. There is no evidence that muscle spindles or Golgi tendon organs are concerned with muscle pain. Of the remaining receptors within muscle, free nerve endings are most likely to be responsible but the occasional paciniform corpuscles might also function as pain receptors (Barker, 1962), as might sensory receptors in the walls of intramuscular blood vessels, for the larger limb arteries, at least, are painful when pierced with a needle. One point that is of interest is that when a pain spot is encountered within the muscle it is sometimes found that there is an increased resistance to the advance of the needle at this point, suggesting that the receptors may be associated with intramuscular fascial planes. Paintal's experiments 
are again relevant, for he found that only five out of 10 pressure pain receptors associated with the cat gastrocnemius-soleus, were actually within the muscle bellies, the remainder being in the region of the musculotendinous junction or associated with the overlying fascia.

Rather more is known about the afferent fibres from pressure-pain receptors. In the cat these fall mainly within the group III range ( 1 to $4 \mu$ diameter, conducting at rates below $24 \mathrm{~m} / \mathrm{sec}$ (Paintal, 1960; Bessou and Laporte, 1961) and according to Paintal they account for the greater part of the group III input from muscle. However some pressure pain receptors connect to group II fibres and a few to group I (Paintal, 1960), and Iggo (1961) has described receptors responding to localized heavy pressure whose afferents are non-myelinated. So far as man is concerned, the findings presented in this paper suggest that, like the cat, pain from human muscle is transmitted mainly along small nerve fibres. On the present evidence, however, it is possible only to say that the majority probably have diameters substantially smaller than the fibres supplying extrafusal muscle fibres.

My thanks are due to Dr. P. M. Fullerton and Dr. C. D. Marsden for their helpful comments on reading this paper.

\section{REFERENCES}

Barker, D. (1962). The structure and distribution of muscle receptors. In Symposium on Muscle Receptors, pp. 227-240. Edited by D. Barker. Hong Kong University Press: Hong Kong.

Bessou, P., and Laporte, Y. (1961). Some observations on receptors of the soleus muscle innervated by group III afferent fibres. J. Physiol. (Lond.), 155, 19P.

Gasser, H. S., and Erlanger, J. (1929). The role of fibre size in the establishment of a nerve block by pressure or cocaine. Amer. J. Physiol., 88, 581-591.

Iggo, A. (1961). Non-myelinated afferent fibres from mammalian skeletal muscle. J. Physiol. (Lond.), 155, 52-53P.

Kellgren, J. H. (1937-8). Observations on referred pain arising from muscle. Clin. Sci., 3, 175-190.

Lewis, T. (1938). Suggestions relating to the study of somatic pain. Brit. med.J., 1, 321-325.

Lewis, T. (1942). Pain, p. 41. Macmillan: New York.

Lewis, T., Pickering, G. W., and Rothschild, P. (1931). Observations upon muscular pain in intermittent claudication. Heart, 15, 359-383.

Meadows, J. C. (1970) Observations on the responses of muscle to mechanical !and electrical stimuli. J. Neurol. Neurosurg. Psychiat., in press.

Nathan, P. W., and Sears, T. A. (1961). Some factors concerned in differential nerve block by local anaesthetics. J. Physiol. (Lond.), 157, 565-580.

Paintal, A. S. (1960). Functional analysis of group III afferent fibres of mammalian muscles. J. Physiol. (Lond.), 152, 250-270.

Woolf, A. L. (1969). Muscle pain. In Disorders of Voluntary Muscle, p. 205-206. Edited by J. N. Walton. Churchill: London. 